
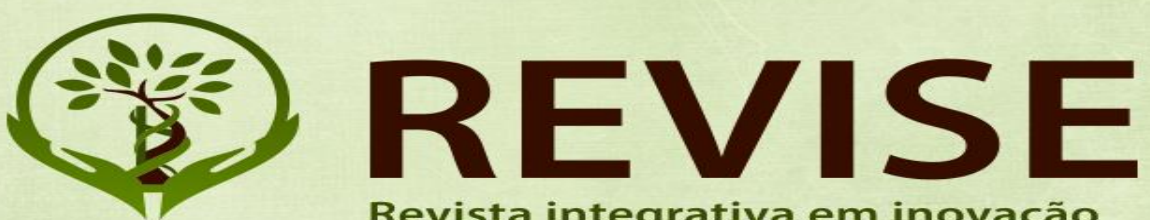

Revista integrativa em inovação tecnológica nas ciências da saúde

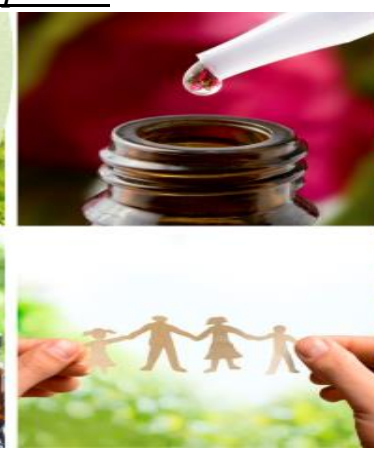

\title{
Conferências: INOVAÇÃO SUSTENTABILIDADE, ECONOMIA CRIATIVA E EMPREENDEDORISMO SUSTENTÁVEL EM ALIMENTAÇÃO E SAÚDE
}

\author{
Sonia Maria Dalcomuni
}

UFES

\section{RESUMO}

O artigo registra as conferências do congresso internacional de inovação tecnológica nas ciências da saúde: a sustentabilidade das práticas integrativas a agroecologia, mais especificamente a conferência Inovação sustentabilidade, economia criativa e empreendedorismo sustentável em alimentação e saúde. A conferência caracterizou a economia global baseada em mentes criativas e valores institucionais de sustentabilidade como fontes de geração de riqueza. O evento aconteceu de 15 a 18 de novembro de 2017 no IFBA SAJ sob a direção da Universidade Federal do Recôncavo da Bahia.

Palavras-chave: Sustentabilidade. Inovação. Economia Criativa. Alimentação. Saúde.

\begin{abstract}
The article records the conferences of the international congress on technological innovation in health sciences: the sustainability of integrative practices in agroecology, more specifically the conference Innovation sustainability, creative economy and sustainable entrepreneurship in food and health. The conference characterized the global economy based on creative minds and institutional values of sustainability as sources of wealth generation. The event took place from November 15 to 18, 2017 at IFBA SAJ under the direction of the Federal University of Recôncavo da Bahia.

Keywords: Sustainability. Innovation. Creative economy. Food. Health.
\end{abstract}



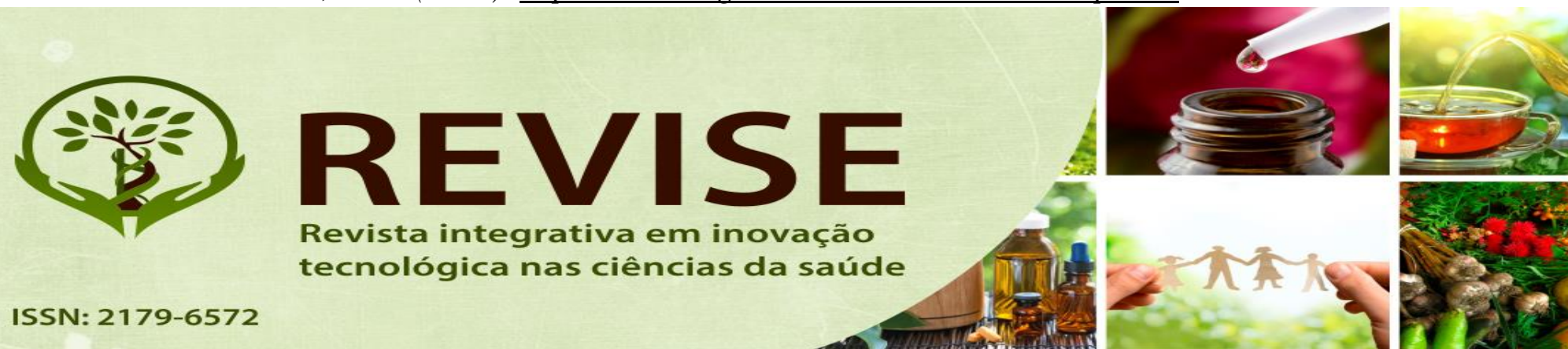

ISSN: 2179-6572

Revista integrativa em inovação tecnológica nas ciências da saúde

No contexto da sociedade do conhecimento que caracteriza a economia global da atualidade, mentes criativas e valores institucionais de sustentabilidade são fontes de geração de riqueza, substituindo, em centralidade, os clássicos fatores de produção: terra, trabalho e capital. Supõe-se que a economia criativa seja o grande motor do desenvolvimento mundial no século XXI. Tema relativamente novo na academia e pouco presente nas políticas econômicas, representa uma transição da "economia da escassez" dos recursos naturais limitados, para a "economia da abundância" tendo como fonte principal a criatividade humana.

Identificam-se as abordagens da economia criativa como em duas fases, quais sejam: pré 1970, fortemente centrada na exploração econômica das atividades culturais (as denominadas "indústrias culturais" inspiradas especialmente nas produções de cinema de Hollywood, música, teatro, e parques da Disney, nos Estados Unidos); e, pós 1990, a partir de conceituações desenvolvidas na Austrália e, principalmente adaptações e implementação de políticas da Inglaterra que extrapolaram as tradicionais indústrias culturais, incorporaram novos segmentos produtivos decorrentes do Paradigma das Tecnologias de Informação e Comunicação, como a produção de softwares e games virtuais. Ilustrativo neste sentido, Hollywood responde por $85 \%$ da produção cinematográfica mundial girando cifras da ordem de U\$70 bilhões /ano e a produção de softwares na Índia que responde por uma geração de renda da ordem de U\$20 bilhões/ano.

A economia criativa apresenta-se como um novo e amplo espectro de oportunidades de promoção de riqueza social na perspectiva de mitigação da pressão sobre os recursos naturais como fatores de produção, buscando-se produtos de reduzido conteúdo material (quase - imaterialidade da produção) e alto valor agregado. Assim, cinema, teatro, música, turismo, softwares, gastronomia, games, artesanato, joalheria são alguns dos muitos segmentos que compõe a economia criativa e que podem ser elencados enquanto alvo para o estímulo ao empreendedorismo sustentável. 

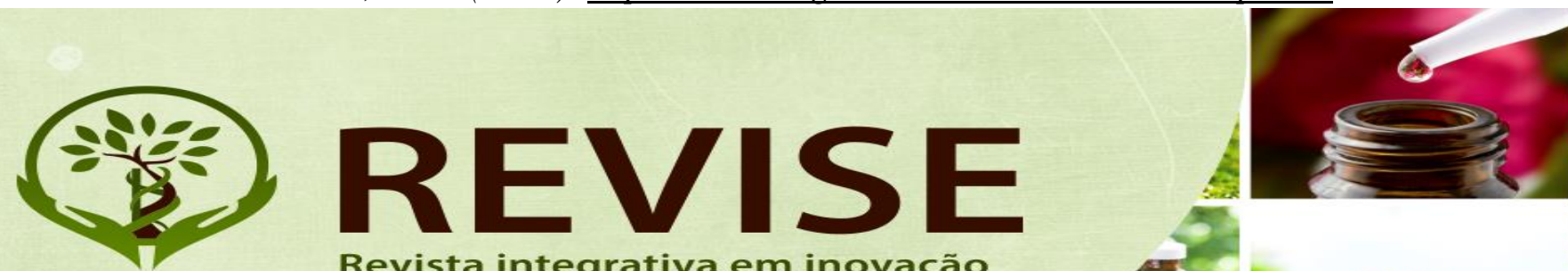

Revista integrativa em inovação tecnológica nas ciências da saúde

ISSN: 2179-6572

\section{Discurso da conferencista:}

Todos se perguntam: o que é a economia criativa? Economia criativa não seria algo relacionado a artesanato? Economia criativa a partir de 1987 que foi quando o governo britânico formou o seu Plano Nacional de Economia Criativa, que passou a ser repensado como uma nova vertente de promoção de desenvolvimento econômico social conciliando as bases de inovação e sustentabilidade. Historicamente a economia criativa envolve transações que tem a criatividade como fator chave. As atividades econômicas da economia criativa contribuem, por exemplo para fazer reduzir a pressão negativa sobre o ambiente natural; a produção de fitoterápicos, por exemplo, como também as atividades produtivas que recuperam o ambiente.

$\mathrm{Na}$ discussão que vai na vertente do debate em saúde, equivale a priorizar a prevenção da doença e promoção da saúde em contraposição à remediação na urgência/emergência. Desde os primórdios da humanidade, tecnologias são desenvolvidas objetivando melhorar a vida humana na terra. As novas tecnologias selecionadas pelo mercado, são sempre mais eficientes que as anteriores, considerandose os objetivos que nortearam seu desenvolvimento e adoção, o que não significa que serão sempre ambientalmente mais sustentáveis. Por exemplo, um canhão é mais eficiente que um fuzil, na função de matar; assim como bomba atômica é superior as duas, apresentando maior poder de destruição que as duas anteriormente mencionadas. Portanto, é importante compreender que é falsa a ideia de que todo desenvolvimento tecnológico será sempre ambientalmente melhor. Para ele ser melhor em uma determinada perspectiva no desenho da agenda científica e no desenvolvimento da tecnologia, o policy maker tem que desenhar o objetivo. Assim para ser ambientalmente superior a dimensão ecológica tem que estar previamente presente na agenda de seu desenvolvimento. Os desafios contemporâneos são trabalhar criatividade, ciência e tecnologia em uma perspectiva de rede para promoção no desenvolvimento econômico mais bem qualificado, ambientalmente mais adequado. 

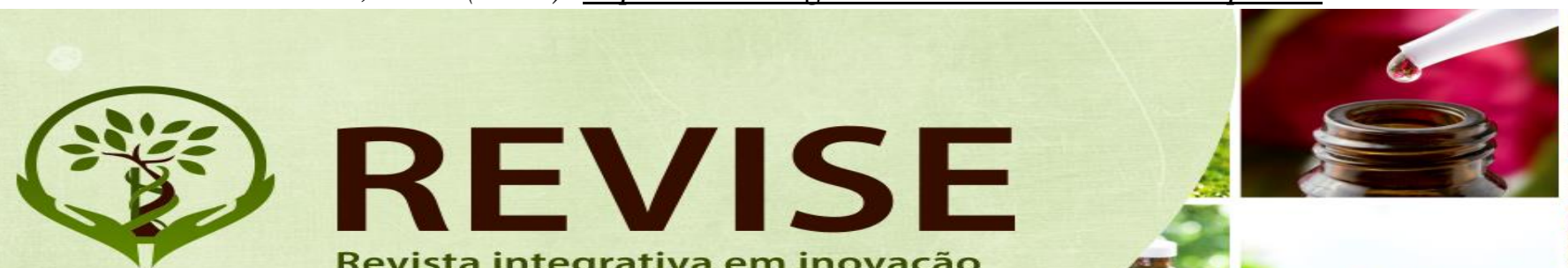

Revista integrativa em inovação tecnológica nas ciências da saúde

ISSN: $2179-6572$

E por que que tem que haver desenvolvimento econômico? Porque a população cresce, diversificando suas necessidades. Assim a economia criativa pode ser trabalhada de uma forma construtiva como um novo vetor de promoção de desenvolvimento econômico. Na medida em que se melhora o meio ambiente, o país com seu meio ambiente mais sustentável aumenta suas possibilidades de gerar riqueza. E tende a ter uma população mais saudável.

A humanidade assumiu um pacto, o pacto de que a procriação é um direito universal do ser humano. Então nisso ninguém deve mexer. Assim é preciso sempre considerar que a população vai crescer e as necessidades de provimento de bens materiais e imateriais crescem proporcionalmente. Então, o gestor responsável pelo desenvolvimento econômico tem que direcionar a necessidade de provimento às diversas áreas do conhecimento para criar novas formas do fazer humano institucional. Os profissionais trabalham na questão de impacto ambiental, como também na expectativa da qualidade de vida no contexto de um planeta fechado e de um planeta finito. O planeta não cresce ele é um só; imaginava-se, no passado, até a década de 1960, por exemplo, que poderíamos explorar indefinidamente os recursos naturais, numa perspectiva de que o nosso planeta fosse infinito, assim como seria infinita a disponibilidade de recursos naturais

Com o passar do tempo as pessoas mantém hábitos que não condizem mais com as novas formas do fazer humano. Não só o crescimento e a concentração populacional, mas também a evolução tecnológica ao longo dos tempos requer uma mudança nos hábitos e costumes em sociedade. Por exemplo, antigamente era orientado pelas áreas de saúde do setor público que os dejetos domésticos fossem lançados nos cursos d'agua. Enquanto a população é reduzida isso não traz problemas ambientais, pois os cursos d'água apresentam resiliência o suficiente para depurar essa água a despeito destes dejetos: eles se diluem. Porém com o adensamento populacional, por exemplo, milhões de pessoas concentradas, em áreas geográficas específicas, ao lançarem seus dejetos domésticos nos cursos d'água, comprometem indelevelmente sua 

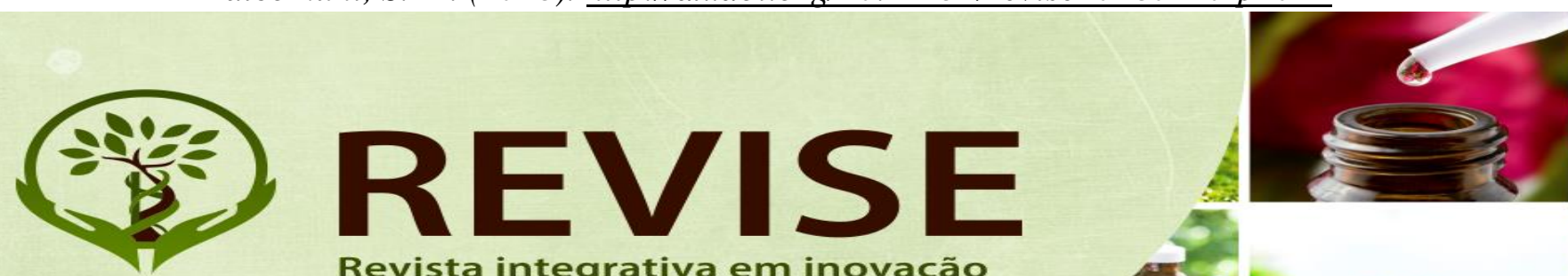

Revista integrativa em inovação tecnológica nas ciências da saúde

ISSN: $2179-6572$

resiliência, sua capacidade de autodepuração: problema dramático de saúde pública. O principal problema ambiental do Brasil hoje, é justamente as carências em tratamento de esgoto. Em termos de empreendedorismo sustentável o Brasil apresenta uma enorme potencialidade de desenvolvimentos de negócios nos mais diversos segmentos, devido à sua gigantesca dimensão geográfica, diversidade de solos, de clima e de biodiversidade. Por exemplo o Brasil é o melhor país do mundo em termo de aptidão para energia solar, A definição de investimentos em energia solar no Brasil traz o potencial de transformar o país em um líder na produção desta modalidade renovável e limpa de energia.

A economia criativa insere-se nessa vertente de promoção do crescimento econômico com o foco na sustentabilidade. A economia criativa transita da economia da escassez para a economia da abundância, em que os recursos naturais são escassos, e por exemplo utilizados obedecendo-se sua capacidade de resiliência. O principal fator de produção na economia criativa é a criatividade e tal qual o conhecimento, esse é um insumo que quanto mais é utilizado, ao invés de esgotar-se, se amplia Exemplificando: se você tem uma maçã e você come a metade dessa maçã, sobra-lhe apenas a outra metade, ou seja apenas meia maça. Porém se você tem uma ideia e compartilha, essa ideia tenderá a ser ampliada e multiplicada com feedbacks. Então algo para se refletir sobre o nosso significado enquanto sociedade. É preciso ressignificar a criação de possibilidades da economia: de transitar em uma área que tem a capacidade de criar coisas, na economia da abundância. Na abundância, o empreendedorismo sustentável no que se refere à produção de alimentos, outro exemplo, constitui-se em produzir e preparar o alimento de forma sustentável e saudável, com sustentabilidade ambiental e processamento dos alimentos com criatividade. A agroecologia e a gastronomia, por tanto são também áreas que podem ser desenvolvidas numa perspectiva de empreendedorismo sustentável assentado nos princípios da economia criativa.

A economia criativa, portanto, engloba uma gama de outras possibilidades de desenvolvimento de empreendedorismo sustentável, considerando-se apenas a produção 

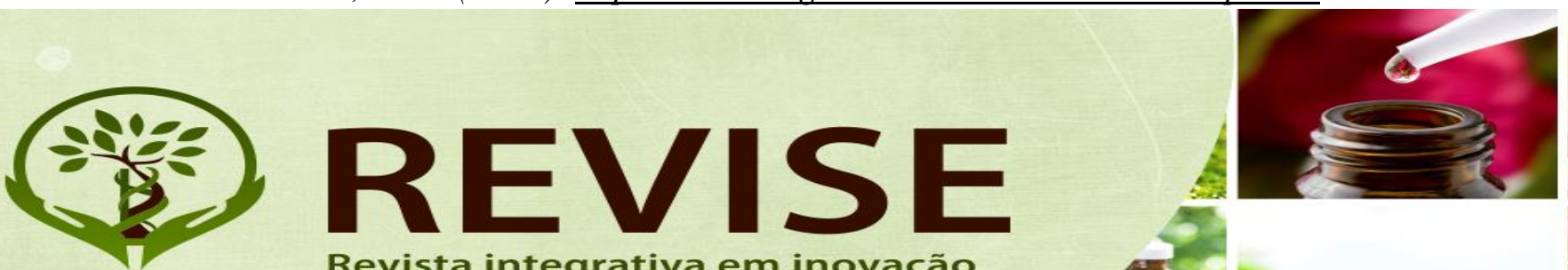

Revista integrativa em inovação tecnológica nas ciências da saúde

ISSN: $2179-6572$

agrícola florestal, como também a exploração da biodiversidade brasileira, uma das maiores riquezas atuais.

Assim, voltando o foco ao tema central da área de saúde, esta figura como objetivo final de todas as bases anteriores, já que desenvolvimento sustentável é vida e vida com qualidade. Outra peculiaridade da criatividade, por sua vez, refere-se à sua característica de economia do intangível: deixa-se de pressionar mais fortemente a base material economizando, os recursos naturais que são limitados.

A economia criativa depende do design (projeto) e do uso das tecnologias de modo a utilizar o desenvolvimento tecnológico a seu favor, em uma escala de desenvolvimento compatível com a capacidade ecológica do planeta. Finalizando, não há como falar de vida/sustentabilidade, sem falar da água que é a base de tudo. Assim ações voltadas para a manutenção/melhoria da quantidade e qualidade da água cria um leque enorme de possibilidade de atuação. As ações como proteção e recuperação de nascentes, construção de reservatórios, recomposição de matas ciliares apresentam potencial para empreendedorismo sustentável.

Reiterando, a produção de alimento em base agroecológica são algumas das oportunidades de empreendimento. O desenvolvimento sustentável, no atual contexto de complexidade tecnológica, requer capacitação de recursos humanos para cooperação, ciência e tecnologia verdes e empreendimento que minimize a pressão sobre recursos naturais e em ações de reparos de degradações ambientais. Recursos que ampliem a geração de riquezas e empregos através da priorização de ativos intangíveis integrando a ação do estado, das empresas e dos indivíduos. O desafio é grande, mas as oportunidades também o são. Mãos à obra todos nós. Muito obrigada!”

\section{Vídeo transmitido:}

O Brasil tem uma das maiores bacias hidrográficas do planeta. O país tem problemas na preservação, distribuição e no uso dos recursos hídricos. O problema se encontra decorrente ao irracional uso de defensivos agrícolas nas lavouras e muito lixo. 

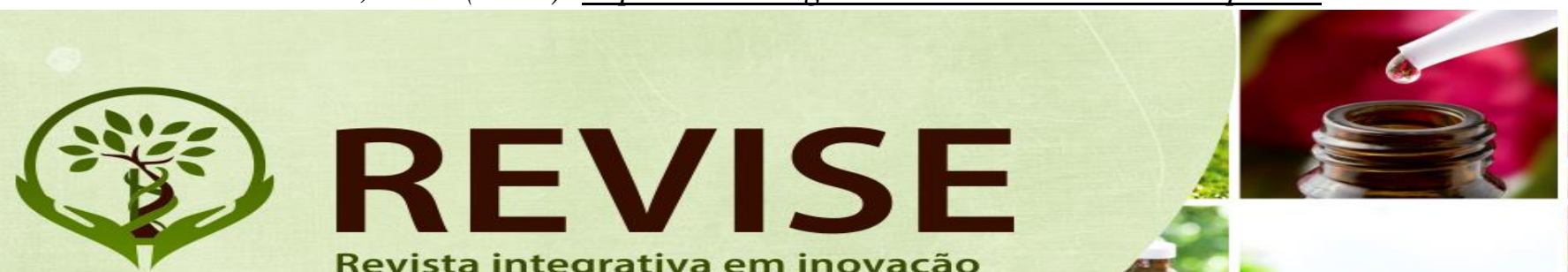

Revista integrativa em inovação tecnológica nas ciências da saúde

ISSN: 2179-6572

Existem milhões de pessoas, a maioria crianças que irão morrer por doença de veiculação hídrica até o ano de 2020. Isso significa uma média de 5 milhões de pessoas ao ano, por falta de água potável e saneamento básico. Nós temos que melhorar os hábitos e desperdício. Devemos racionalizar como se lava o carro, como se lava uma calçada, tudo isso precisa ser repensado.

As famílias precisam se conscientizar que a economia que ela fizer vai refletir no sistema de água e assim uma cadeia de preservação, conservação de recursos naturais. Pequenas ações podem auxiliar a preservação da água, por exemplo: uma "pingueira" desperdiça em torno de 50 litros de água/dia e 1.500 litros por mês. Imagine uma torneira pingando como na casa dos 190 milhões de brasileiros; o problema é muito grave. Mas existem soluções: nós temos vários equipamentos em criação em laboratórios das universidades para diminuir o excesso de consumo, como por exemplo, as caixas acopladas nos banheiros que gera uma descarga hídrica, com uma economia de quase $1 / 3$ ou até $25 \%$ de água.

Segundo a ONU, a falta de água para consumo afeta mais de 1 bilhão e meio de pessoas no mundo, a cada 8 segundos morre uma criança por causa relacionada a saneamento com água poluída, $70 \%$ dos leitos dos hospitais em todo mundo são ocupados por doenças dessa natureza, $80 \%$ de doenças como febre amarela, esquistossomose por exemplo são veiculadas por problemas com água contaminada: a questão é saneamento básico. Muitas dessas doenças poderiam ser evitadas e o mais importante salvando vidas. No Brasil morre por ano 50 mil bebês decorrentes de doenças diarreicas que em sua maioria são provocadas pela água contaminada. Já é pesquisa conhecida no mundo que cada dólar investido no saneamento básico se economiza 4 dólares na saúde. Praticamente metade da população no mundo não tem acesso a saneamento. 